\title{
Developing an eBoard for resource management in the Image Guided Therapy Department
}

\author{
$\underline{\text { P.A. Khaiter }}^{\text {a }}$, M.G. Erechtchoukova ${ }^{\text {a }}$, B. Connolly ${ }^{\text {b }}$, A. Aziza ${ }^{\text {b }}$, K.S. Ahmed ${ }^{\text {a }}$ D. Khaiter ${ }^{\text {a }}$ and \\ B. MacLellan ${ }^{b}$ \\ a School of Information Technology, Faculty of Liberal Arts and Professional Studies, York University, \\ Toronto, Canada \\ Email: pkhaiter@yorku.ca \\ ${ }^{b}$ Department of Diagnostic Imaging, The Hospital for Sick Children, Toronto, Canada
}

\begin{abstract}
The health care sphere presently faces a number of challenges. There is a steady necessity to improve the quality of services and to reduce their cost. Information technologies are an important factor in responding to these challenges. Health information systems are aimed to capture, store, manage and communicate information related to health at individual and population levels or the activities of organizations working within the health sector. The unique features of the e-health systems are rooted in the inherent confidentiality issues and diversity of the stakeholders involved in both development and utilization of the systems comprising of patients, doctors, nurses, administrators, scientists, payers, and regulators. Because of this diversity, health informatics is a multi-disciplinary field combining information science, computer science, economics, social science, epidemiology, behavioral science, public health and medicine.
\end{abstract}

Operations of the Image Guided Therapy (IGT) Department of the Hospital for Sick Children ("SickKids"), Toronto, Canada have been investigated in the study. IGT provides valuable diagnostic and therapeutic data using procedures that involve different forms of anesthesia or sedation administered to the patients. Procedures done at the IGT can be divided into three major groups: (1) general anesthetic (GA) cases, which require complete anesthesia of the patient; (2) registered nurse (RN)-sedation or non-GA cases, which do not require complete anesthesia; and (3) local cases done under local anesthesia. The department works with three main groups of patients: inpatients, outpatients and emergency cases. There are also different types of imaging produced: ultrasound, fluoroscopy/digital subtraction angiography and computerized axial tomography (CT/CAT scan).

The coordination of departmental resources and scheduling procedures is a necessary step in improving the efficiency of the department's operation. At present, IGT utilizes a manual version of the operation board to facilitate communications and coordination of all the resources, including radiologists and fellows, anaesthesiologists, technologists and nurses as well as operation, observation and consultation rooms, etc.

A computer-based application called "eBoard" implementing board functions is suggested. It can be considered as a transaction processing system which stores and updates necessary data and delivers them in an organized form on request. The application does not require complex computational algorithms for data processing. The data manipulation operations include capturing and entering the data stored in a database, retrieving the data and organizing them in a predefined format. For such types of data processing activities, the utilization of CASE tools is warranted and can be very beneficial. Given that this system should be integrated with other departmental and hospital information systems, the principles of modularity and extensibility of software components become essential.

The object-oriented approach (OOA) in combination with the Unified Modeling Language (UML) have been applied in the development of the eBoard information system for the IGT department. An obvious advantage of the UML is the availability of multiple commercial and free code-generating and round-trip engineering CASE-tools. As a comprehensive design, modeling and development CASE tool supporting the OOA and integrated with the UML, IBM ${ }^{\circledR}$ Rational ${ }^{\circledR}$ Software Architect was selected.

Although many IT projects in health care do utilize the UML, it is possible to conclude that a common methodology or standardized framework to do so is still lacking. This issue needs a further elaboration and will be addressed in the presentation. The paper is intended to inspire and shape the discussion within the session on "Health Information Systems: Challenges and Solutions".

Keywords: Health information system, Unified Modeling Language (UML), Actor, Use case 


\section{INTRODUCTION}

The application of information systems and, broadly, information technology, is an instrument for improving the quality and cost reduction in health care provision. A successful implementation of health information systems faces a number of challenges. The complexity of health care processes, lack of standards, redundancy of data and applications, lack of interoperability, vendor lock-in, portability, platform independency, high cost and distributed environment are among them (Raghupathi and Umar, 2008).

In this paper, we argue for the object-oriented approach to the health systems development in combination with the Unified Modeling Language supported by a CASE tool as a means to overcome these challenges. A digital version of the operation board ("eBoard") project for the Image Guided Therapy (IGT) Department of the Hospital for Sick Children ("SickKids"), Toronto, Canada is used as a case study. The advantage of the eBoard is in providing real-time feedback on the status of both patients and team members and accessibility to every staff member from their respective workplaces.

\section{METHODS}

Likewise any other undertaking in IT, health care systems development requires a certain standard set of steps leading towards systems deployment and designated utilization. A framework commonly used in software engineering is the systems development life cycle (SDLC).

\subsection{The SDLC}

Fundamentally, the SDLC consists of four clearly defined and distinct phases: (1) project planning and initiation; (2) analysis; (3) design; and (4) implementation (Dennis et al., 2012). Each phase is composed of related activities. In turn, activities are spelled out in the corresponding tasks. In retrospect, a number of SDLC models have been suggested, but all of them can be classified in one of the three groups: (1) traditional (structured) paradigm; (2) information engineering paradigm; and (3) object-oriented paradigm (Figure 1).

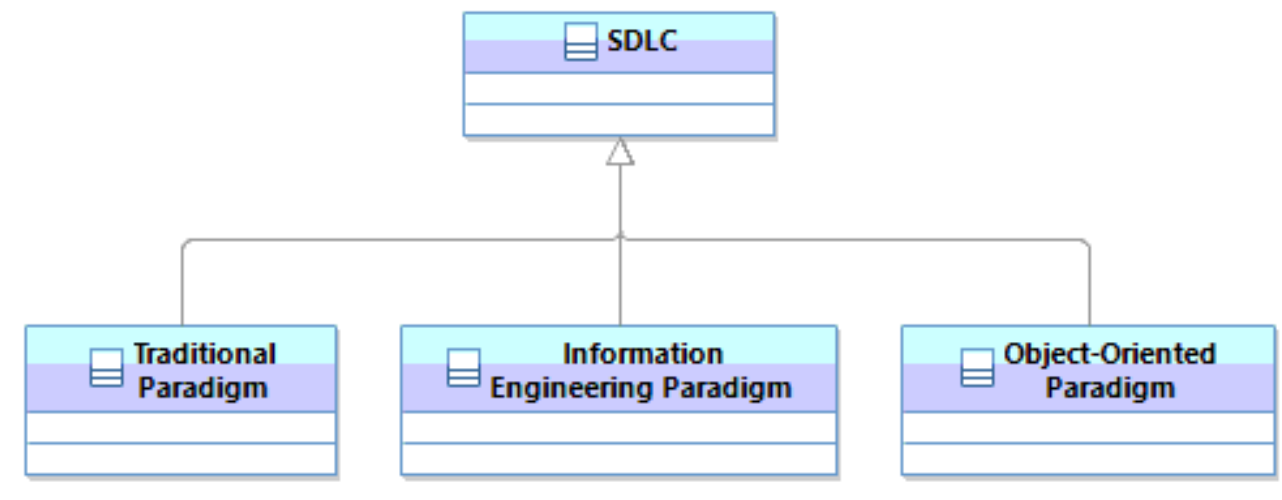

Figure 1. Paradigms of the SDLC shown as a UML class diagram.

In this research, we adopted the object-oriented approach (OOA) to the SDLC due to a common perception that modelling of real-world systems in terms of objects is natural to people (Booch et al., 2007) and because of its consistency with the important design principles, such as re-usability, protection from variations, indirection, object responsibility, etc. (Satzinger et al., 2012). The OOA has been successfully applied in specialized health information systems in cardiology, ophthalmology, anesthesiology, clinical laboratories, medical imaging and telemedicine (Aggarwal, 2002). Also, the OOA is supported by, and fully integrated with, the Unified Modeling Language (UML).

\subsection{The UML}

The UML is a standardized graphical language being used in object-oriented software engineering for specifying, documenting and visual modelling of an IT project's artifacts or components (Fowler, 2004; Rumbaugh, 1999). The UML provides graphical notation to model an information system being built. The complexity of modern software development cannot be captured by a single diagram. The UML offers different types of diagrams to address all the aspects of the system. These diagrams are classified into structure diagrams and behaviour diagrams. The latter group also includes a subset of interaction diagrams. 
The most recent version of the language, UML2.x, totals 14 graphical models subdivided into seven structure diagrams, three behaviour diagrams and four interaction diagrams.

\section{IMAGE GUIDED THERAPY (IGT) DEPARTMENT: OPERATIONS AND RESOURCES}

We consider operations of the Image Guided Therapy (IGT) Department of the Hospital for Sick Children ("SickKids"), Toronto, Canada, which provides valuable diagnostic and therapeutic data using procedures that involve different forms of anesthesia or sedation administered to the patients. Procedures done at the IGT can be divided into three major groups: (1) general anesthetic (GA) cases, which require complete anesthesia of the patient; (2) registered nurse (RN)-sedation or non-GA cases, which do not require complete anesthesia; and (3) local cases done under local anesthesia. The department works with three main groups of patients: inpatients, outpatients and emergency cases. There are also different types of imaging produced: ultrasound, fluoroscopy/digital subtraction angiography and computerized axial tomography (CT/CAT scan).

The coordination of departmental resources and scheduling procedures is a necessary step in improving the efficiency of the department's operation. At present, the IGT utilizes a white board with markers to facilitate communications and coordination of all the resources including radiologists and fellows, anaesthesiologist, technologists and nurses as well as operation, observation and consultation rooms, etc. The Board is run manually by the "board runner", one of the technologists, taking their turns as a board runner according to a predefined schedule. The operational schedule is prepared manually the night before based on received requests and available resources, and is originally recorded using an internal departmental information system. The patient information coordinator ("Scheduler") prints out the schedule for the next day and writes it on the Board using erasable marker at the end of the day. The Board provides information about the patients (e.g., name, ID, age, type), their progression though the stages (e.g., arrived, went for blood work), type of operations/procedure, anaesthesia or sedation required, referring physician, starting time of the procedure, status of the procedure (e.g., “call has been made to the transportation team”).

The information on the board starts with basic data, such as the date, radiologist, anaesthesiologist and fellow available for the day, etc. Then, the board contains the column of operations stating the case of procedure on the top (e.g., GA or Sedation). It also indicates a radiologist responsible for the procedure and the room in which this procedure will take place. An anaesthesiologist scheduled for that particular room is also mentioned. For each patient, the Board shows the planned starting time of the procedure followed by the name of the patient, patient ID, age and an indication of the type of patient (e.g., in/out patient). On the next line, it shows the procedure type followed by the name of the referring physician. The block for a patient ends with the check box of consent and report of the blood work or any other test results associated with the procedure that might be needed for the radiologists. On the left hand side of each patient block, certain notes are written by the board runner, e.g., "C" means a call has been made to the ward to prepare the patient, "T" denotes that a call has been made to the transportation team to bring down the patient to the IGT. The tick sign beside the time indicates that the patient is at the IGT and "went for blood work" meaning that the patient arrived but went to complete a blood test. A sample view of the operation board is given in Figure 2.

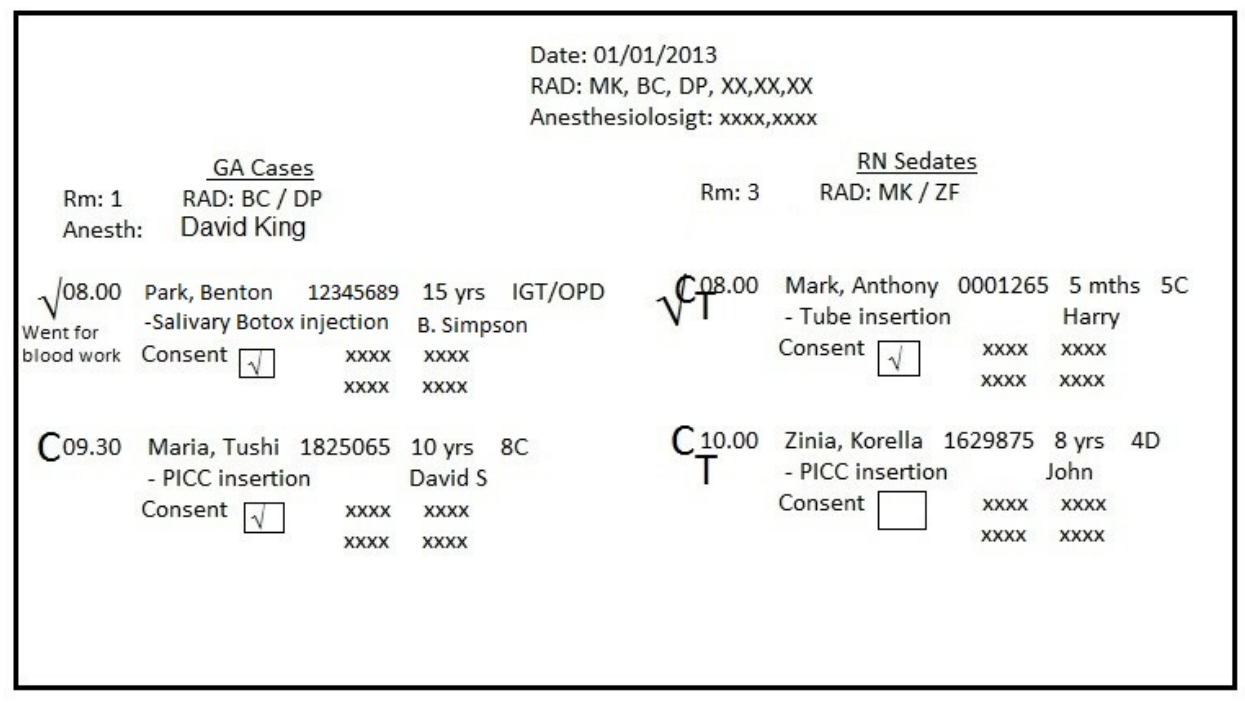

Figure 2. A sample view of operation board (all names and IDs are not real). 
Khaiter et al., Developing an eBoard for resource management in the Image Guided Therapy department

All team members (e.g., radiologist, nurse, etc.) provide input or write on the board when they have completed a particular task or if they need to notify of something (e.g., going for a break). For example, when a patient arrives and reports at the reception desk, the receptionist notifies the board runner or updates the board themselves by placing a tick mark $(\sqrt{ })$ beside the name of the patient. Then, a nurse comes to see who is at the waiting room, takes the patient in and prepares for the procedure.

It should be noted that the department has a local computer network consisting of several PCs located in different rooms and has sufficient infrastructure to connect mobile computer devices to that network. Therefore, the manually-run operation Board can be replaced by a computer-based application implementing board functions and facilitating communications between team members in the department.

\section{EBOARD: CONCEPT}

It is desirable to implement a digital version of the Board ("eBoard”) as a centralized information tool. Instead of having one copy of the board in one place, there will be multiple copies of the board in digital format in every place needed. The eBoard will provide real-time feedback on the status of both patients and staff members. Every team member will be able to access information from their respective workplaces and give input or update their status in real-time regime. The eBoard will update and prompt health care providers on all changes in the department and serve the purpose of an effective coordinating tool.

Table 1. Actors and their use cases

\begin{tabular}{|c|c|c|}
\hline Actor & Description & Use case \\
\hline Radiologist/Fellow & $\begin{array}{l}\text { A physician specializing in radiology, completing } \\
\text { procedures at the IGT/working with the radiologist } \\
\text { for training purposes }\end{array}$ & $\begin{array}{l}\text { Select patient } \\
\text { Select room } \\
\text { Update patient status } \\
\text { Update procedure status } \\
\text { Update documentation status }\end{array}$ \\
\hline Technologist & $\begin{array}{l}\text { Highly skilled and certified personnel operating } \\
\text { equipment and capturing images during procedures }\end{array}$ & $\begin{array}{l}\text { Select patient } \\
\text { Select room } \\
\text { Update room status } \\
\text { Update documentation status }\end{array}$ \\
\hline Anaesthesiologist & $\begin{array}{l}\text { A physician who administrates anaesthesia to the } \\
\text { patients and is responsible for the entire time that } \\
\text { the patient is under anaesthesia }\end{array}$ & $\begin{array}{l}\text { Select patient } \\
\text { Select room } \\
\text { Update room status } \\
\text { Update documentation status }\end{array}$ \\
\hline Nurse & $\begin{array}{l}\text { Highly qualified, certified and trained staffs to take } \\
\text { care of the patients before, during and after a } \\
\text { procedure }\end{array}$ & $\begin{array}{l}\text { Select patient } \\
\text { Select room } \\
\text { Update patient status } \\
\text { Update procedure status } \\
\text { Update documentation status }\end{array}$ \\
\hline Receptionist & $\begin{array}{l}\text { A patient information coordinator who works on } \\
\text { the front desk to communicate with patients and } \\
\text { actors of the IGT }\end{array}$ & $\begin{array}{l}\text { Select patient } \\
\text { Update patient status }\end{array}$ \\
\hline Board runner & $\begin{array}{l}\text { A technologist who manages and updates the board } \\
\text { according to the inputs from other actors }\end{array}$ & $\begin{array}{l}\text { Select patient } \\
\text { Update test report } \\
\text { Update add on } \\
\text { Notify actors }\end{array}$ \\
\hline PSA & Patient Service Aide & $\begin{array}{l}\text { Select room } \\
\text { Update room status }\end{array}$ \\
\hline TP & Transportation Person & Update patient status \\
\hline
\end{tabular}

As soon as a job is completed, each team member will be automatically notified about his/her next assignment. For example, when a patient arrives, the receptionist will pull out the schedule from the system and update the status of the patient, displaying it on all of the screens. A nurse will come from the observation room to take the patient in and update the system accordingly. This will prompt the anaesthesiologist that s/he is the next doctor to visit the patient. Once the nurse is done with the patient, the anaesthesiologist will know the status from the control room and proceed directly to the observation room to see the patient. There are good reasons to expect a better operability of the department.

The proposed eBoard application can be considered as a transaction processing system which stores and updates necessary data and delivers them in an organized form on request. It does not require complex computational algorithms for data processing. The data manipulation operations include capturing and entering the data stored in a database, retrieving the data and organizing them in a predefined format. For 
such types of data processing activities, the utilization of CASE tools is warranted and can be very beneficial. Given that this system should be integrated with other departmental and hospital information systems, the principles of modularity and extensibility of software components become essential. As a comprehensive design, modeling and development CASE tool supporting the OOA and integrated with the UML, IBM® Rational ${ }^{\circledR}$ Software Architect was selected.

\subsection{Requirements collection}

The system requirements were collected over 5 weeks of observations and interviews in the IGT department. Observations were conducted for five days each week during regular hours of operations. Afterhours activities of the IGT team members were not taken into account. The developers investigated existing business processes, clarified requirements by means of interviews with the IGT team members, collected statistical data on daily schedules and their evolution throughout the day.

\subsection{Functional modelling}

Following the OOA, in the first step of software functional modelling, we identified the actors, i.e., external agents, person-roles outside the system that directly interact with the system by supplying or receiving information. For each category of actors, we determined use cases or activities performed by the system in response to their requests. Table 1 presents both actors and corresponding use cases (see also Figure 3).

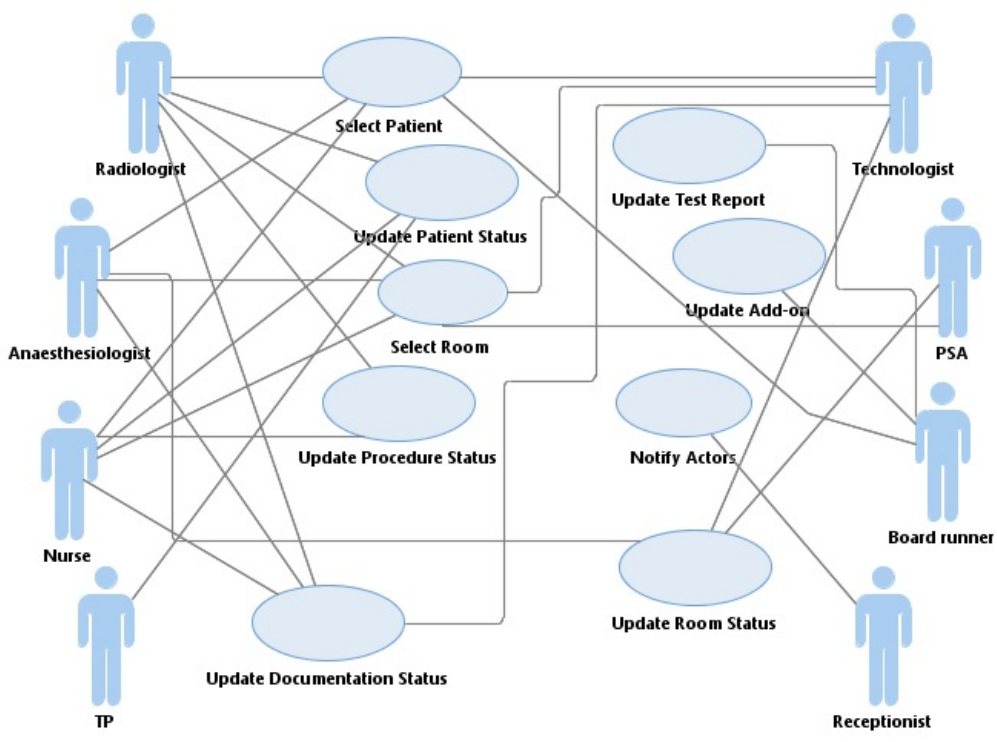

Figure 3. A UML use case diagram for the eBoard system.

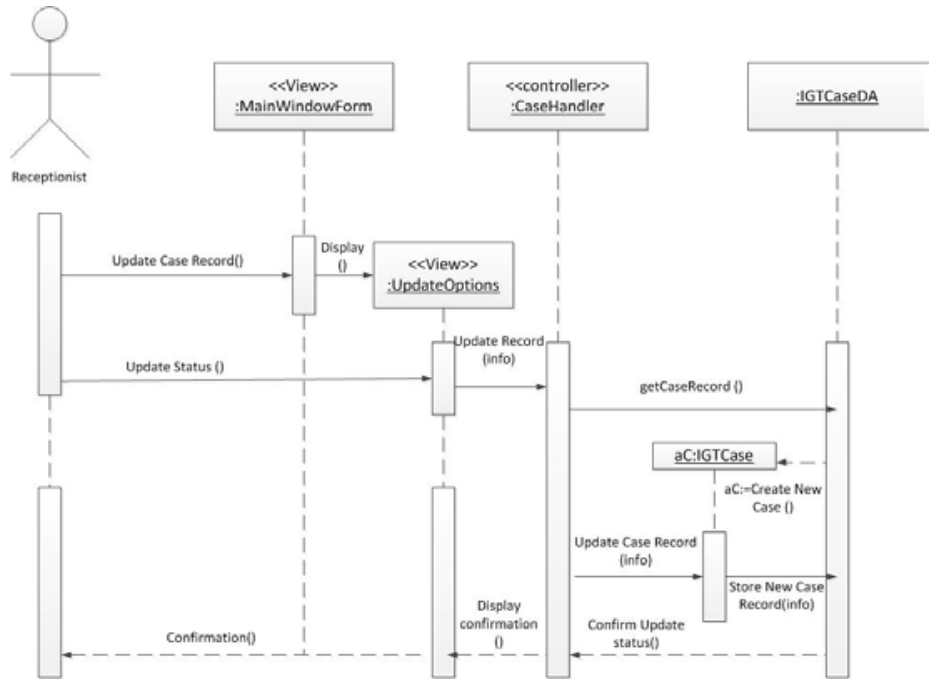

Figure 4. A UML sequence diagram for the eBoard system (Update patient status use case). 
Khaiter et al., Developing an eBoard for resource management in the Image Guided Therapy department

The overall flow of control during the use case execution is modelled by the activity diagrams describing actors or organizational units involved along with their processing steps. Realization of the use cases (i.e., determination of collaborating objects and messages they send to each other to carry out the use case) is done by the sequence diagrams. Figure 4 shows a sequence diagram for the Update patient status use case by the Receptionist actor.

\subsection{System interfaces and prototyping}

Figure 5 shows the system screen when a user is logged in as the Receptionist actor. Figure 6 presents the system screen for the Radiologist actor. A detailed patent log with associated events and their time is demonstrated in Figure 7.

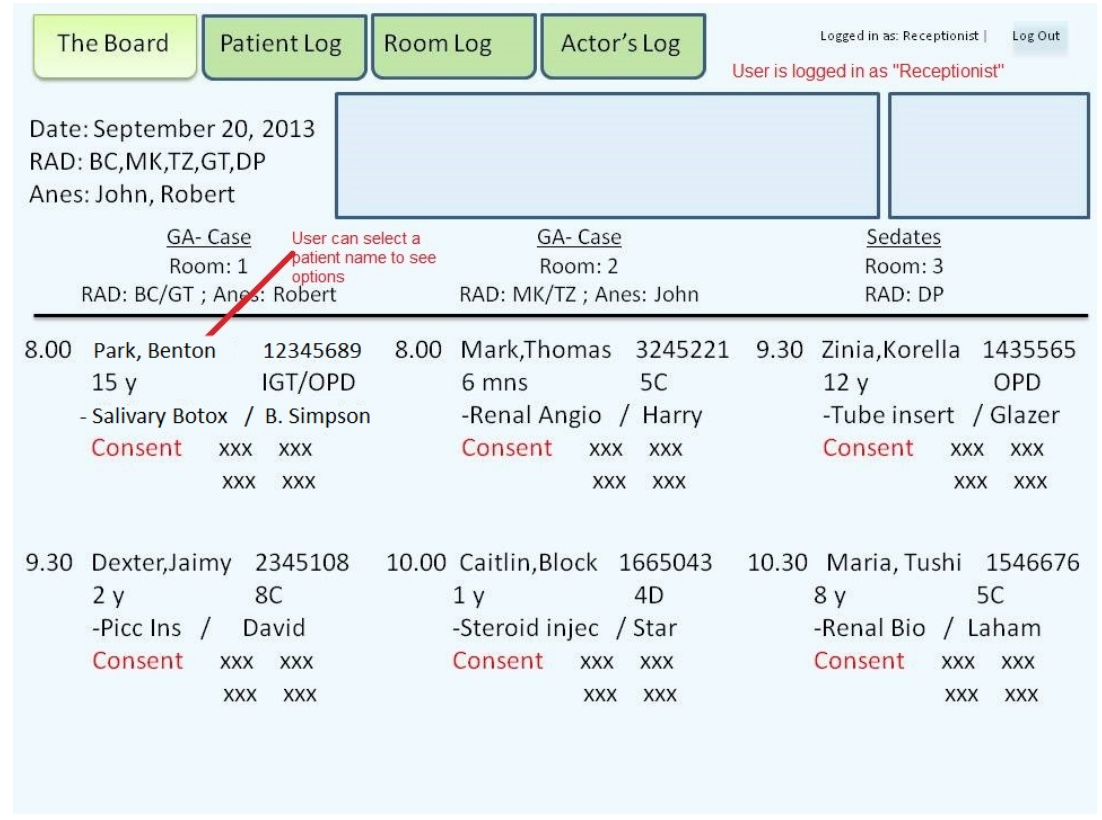

Figure 5. System screen for the Receptionist actor.

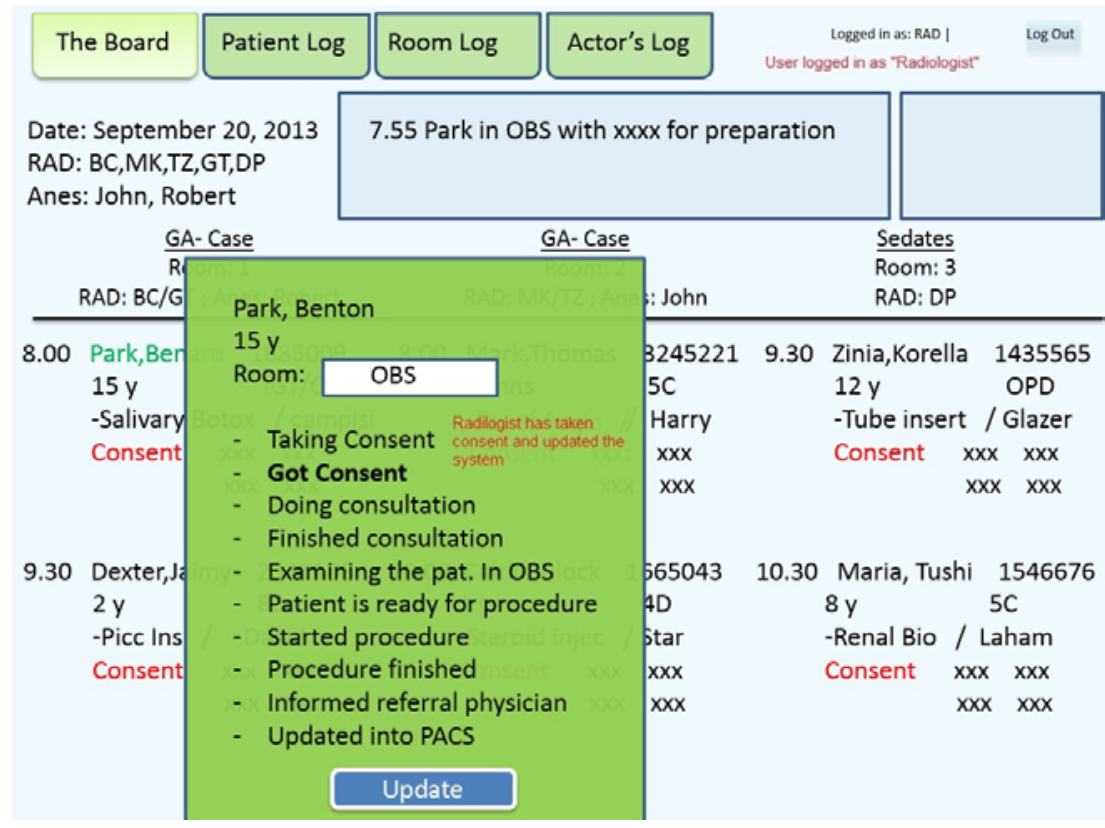

Figure 6. System screen for the Radiologist actor with the options available for the patient. 
Khaiter et al., Developing an eBoard for resource management in the Image Guided Therapy department

\begin{tabular}{|c|c|c|c|c|c|c|}
\hline The Board & \multicolumn{2}{|c|}{ Patient Log } & Room Log & Actor's Log & \multicolumn{2}{|c|}{ Logged in as: RAD | } \\
\hline \multicolumn{2}{|c|}{ Patient lists } & Time & Actor & Event & & Room \\
\hline & & 7.00 & Recep & Arrived in wai & & WA \\
\hline \multicolumn{2}{|l|}{ Park Benton } & 7.05 & Recep & Gone for bloo & & $\mathrm{LAB}$ \\
\hline \multicolumn{2}{|l|}{15 yrs } & 7.50 & Recep & Back from blo & & WA \\
\hline \multirow{3}{*}{\multicolumn{2}{|c|}{$\begin{array}{l}\text { This page is showing all the } \\
\text { events that have happened for } \\
\text { this patient on the day, It is } \\
\text { showing who the actor was and } \\
\text { the time associated with the } \\
\text { event. }\end{array}$}} & 7.55 & Nurse & In OBS for pre & & OBS \\
\hline & & 8.05 & Nurse & Ready to see & logist & OBS \\
\hline & & 8.06 & RAD & Consent taker & & $\mathrm{BR}$ \\
\hline \multirow{2}{*}{\multicolumn{2}{|c|}{$\begin{array}{l}\text { If user clicks "Patient lists", } \\
\text { system will take to the list of } \\
\text { patients on a selected day. }\end{array}$}} & 8.08 & Anes & Examining the & & OBS \\
\hline & & 8.12 & Anes & Ready to see & & OBS \\
\hline & & 8.13 & RAD & Examining the & & OBS \\
\hline & & 8.13 & Tech & Preparing the & & 1 \\
\hline & & 8.13 & Anes & Preparing Ane & & 1 \\
\hline & & 8.15 & Tech & Room is ready & & 1 \\
\hline & & 8.15 & RAD & Patient is reac & & OBS \\
\hline & & 8.16 & Nurse & Procedure sta & & 1 \\
\hline & & 9.15 & RAD & Procedure en & & 1 \\
\hline
\end{tabular}

Figure 7. Patient log with the list of events and their time.

\section{DISCUSSION AND CONCLUSSIONS}

A developed prototype of the system will be used for further refinement of the system requirements to ensure that they meet stakeholder expectations.

The OOA and UML have been applied in the development of the eBoard information system for the IGT department. An obvious advantage of the UML is its support by multiple commercial and free codegenerating and round-trip engineering CASE-tools. Although many IT projects in health care do utilize the UML, it is possible to conclude that a common methodology or standardized framework to do so is still lacking. This issue will be a topic for our future endeavors.

\section{ACKNOWLEDGMENTS}

We are grateful to the entire IGT team for their support of, and contributions to, this project. Part of this work was supported by the Faculty of Liberal Arts and Professional Studies (FLA\&PS) through individual grants.

\section{REFERENCES}

Aggarwal, V. (2002). The Application of the Unified Modeling Language in Object-Oriented Analysis of Healthcare Information Systems. Journal of Medical Systems, 26(5), 383-397.

Booch, G., Maksimchuk, A., Engle, M.W., Young, B.J., Conallen, J., and Houston, K.A. (2007). ObjectOriented Analysis and Design with Applications, $3^{\text {rd }}$ ed., pp. 691. Pearson, Boston.

Dennis, A., Wixom, B.H., and Tegarden, D. (2012). Systems Analysis and Design with UML Version 2.0: An Object-Oriented Approach, $4^{\text {th }}$ ed., pp. 608. John Wiley \& Sons, Hoboken, NJ.

Fowler, M., 2004. UML Distilled: a Brief Guide to the Standard Object Modeling Language, $3^{\text {rd }}$ ed., pp. 208. Addison-Wesley, Boston.

Raghupathi, W., and Umar, A. (2008). Exploring a model-driven architecture (MDA) approach to health care information systems development. International Journal of Medical Informatics, 77, 305-314.

Rumbaugh, J., Jacobson, I., and Booch, G. (1999). The Unified Modeling Language Reference Manual, pp. 550. Addison-Wesley, Reading, Massachusetts.

Satzinger, J.W., Jackson, R.B., and Burd, S.D. (2012). Systems Analysis and Design in a Changing World, $6^{\text {th }}$ ed., pp. 486. Course Technology, Boston. 